Dr Radomir S. Gordić, pukovnik, dipl. inž.

Boriša Jovanović, student,

Đuro Alfirević, student

Vojna akademija - Odsek logistike,
Beograd

\section{IZBOR OPTIMALNOG PUTA ZA KRETANJE ORGANIZOVANOG KOLONSKOG SAOBRAĆAJNOG TOKA NA OSNOVU REZULTATA MODELIRANJA}

UDC: $656.1: 519.863$

Rezime:

U toku planiranja i praktične realizacije zadataka jedinica Vojske SCG često se javlja problem izbora optimalnog puta između dva mesta (čvora) na putnoj mreži. Kriterijumi optimizacije mogu biti različiti. Ovaj projekat treba da omogući brzo i lako određivanje optimalnog puta, primenom dinamičkog programiranja (DP), uz korišćenje Belmanovog (Bellman), algoritma $u$ zavisnosti od izabranog kriterijuma - parametra. Kriterijum optimizacije je minimalno vreme kretanja (putovanja), koje je dobijeno imitacionim modeliranjem kolonskog saobraćajnog toka. Razrađeni algoritam omogućuje izbor optimalnog puta, za bilo koja dva čvora na mreži.

Ključne reči: dinamičko programiranje, optimalni put, Belmanov algoritam.

\title{
CHOOSING AN OPTIMAL ROUTE FOR ORGANIZED VEHICLE MOVEMENT BASED ON MODELING RESULTS
}

\section{Summary:}

During the planing and practical realization of Serbian \& Montenegro units' tasks a problem which often occurs is choosing an optimal transport route between two places (nodes). Optimization criterias can be various. This project should enable quick and easy defining of an optimal route, applzing dynamic programing (DP) using Bellman's alghorithm depending on choosen criteria - parameter. Optimization criteria represent minimun movement time (traveling), whitch are taken from imitational modeling of a traffics queue flow. Operating alghorithm enable choosing an optimal transport route, for any two nodes on a road map.

Key words: Dynamic programing, optimal route, Bellman's alghorithm.

\section{Uvod}

$\mathrm{U}$ realizaciji zadataka saobraćajne podrške (SbP) jedinica Vojske SCG, često se javlja problem određivanja optimalnog puta između dva mesta na putnoj mreži. Kriterijumi optimizacije su različiti. Oni se, u principu, razlikuju u ratnim i mirnodopskim uslovima funkcionisanja SbP.

Poseban problem izbora puta na određenoj mreži javlja se pri kretanju kolo- ne, zbog interakcija između vozila u koloni i delovanja različitih parametara sistema: vozač - vozilo - put - okolina organizacija (V-V-P-O-O), koji su promenljivi u prostoru i vremenu, pa utiču na efikasnost kretanja, a time i SbP.

Postojeća rešenja izbora puta nisu efikasna. U praksi se, pri različitim poremećajima, javlja problem realnosti usvojenih planova, jer se vreme kretanja kolone određuje prostom analitičkom vezom 
između puta i brzine. Takvi planovi predstavljaju idealizovan model saobraćajnog toka, pa se u praksi ne ostvaruju [1].

Ovaj problem spada u klasu zadataka „optimalnog upravljanja“, a realizuje se u okviru funkcije ,planiranje“. Može se rešiti primenom različitih algoritama dinamičkog programiranja. Neki od postojećih algoritama pogodni su i efikasni u računskom smislu, samo za posebne slučajeve izbora najkraćeg puta na odabranoj mreži. Zbog toga, s obzirom na značaj ovog problema sa aspekta realizacije zadataka jedinica Vojske i mogućnosti savremene računarske tehnike, ovaj rad predstavlja korak ka usavršavanju postojećih i razvoju novih metoda optimizacije. Pored toga, učinjen je pokušaj da se izabere optimalan put primenom dinamičkog programiranja, uz korišćenje Belmanovog algoritma. Najkraći put, između izabranih čvorova na putnoj mreži, određuje se na osnovu vremena putovanja koje je dobijeno imitacionim modeliranjem kolonskog saobraćajnog toka $[2,3]$.

\section{Analiza zahteva saobraćajne podrške}

$\mathrm{Na}$ teritoriji gde postoji razgranata putna mreža potrebno je pri planiranju zadataka SbP, na osnovu merodavnog parametra, izabrati komunikacije za kretanje jedinica i kolona, tako da se zadatak realizuje za najkraće vreme. U ovom radu su za merodavne parametre sistema V-V-P-O-O, odabrani:

- maksimalno mogući protok na mreži Q [voz/h],

- moguće brzine kretanja na pojedinim deonicama $\mathrm{V}[\mathrm{km} / \mathrm{h}]$,
- uzdužni nagibi puta ( ,,+“ $i$ za uspon $\mathrm{i}$, ,“ $i$ za pad) u \%,

- koeficijent prianjanja pneumatika sa podlogom $\mu$ (sa aspekta kvaliteta i stanja kolovoznog zastora (KZ)).

Pored toga, pri izboru optimalnog puta neophodno je uzeti u obzir specifičnosti saobraćajnog toka i interakcije koje se javljaju između učesnika u saobraćaju i elemenata sistema V-V-P-O-O.

Radi rešenja iznetog problema uočena je neorijentisana mreža sa $\mathrm{N}$ čvorova (slika 1). Ovako definisana mreža potpuno je određena matricom $X$,

$$
X=\left\|x_{i j}\right\|
$$

gde je $\mathrm{X}$ kvadratna matrica dimenzija $(\mathrm{N} \times \mathrm{N})$, a element $\mathrm{x}_{\mathrm{ij}}$ dužina puta od čvora $\mathrm{P}_{\mathrm{i}}$ do čvora $\mathrm{P}_{\mathrm{j}}$. Ako takav put ne postoji onda je $\mathrm{x}_{\mathrm{ij}}=\infty$ ( slika 1).

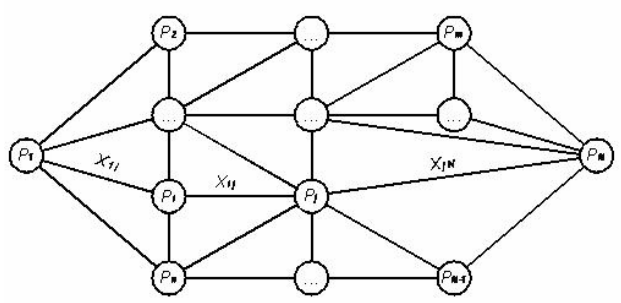

\section{Sl. 1 - Neorijentisana mreža sa N čvorova [1]}

Dužina puta između čvora $\mathrm{P}_{\mathrm{m}} \mathrm{i}$ čvora $P_{n}$ iznosi:

$$
L=\sum_{k=m}^{n} l_{k}[\mathrm{~km}]
$$

gde je $l_{\mathrm{k}}$ udaljenost između susednih čvorova na izabranom putu. 
Vreme putovanja između čvora $\mathrm{P}_{\mathrm{m}} \mathrm{i}$ čvora $\mathrm{P}_{\mathrm{n}}$ iznosi:

$$
T=\sum_{k=m}^{n} t_{k}[\min ]
$$

gde je $t_{k}$ vreme putovanja između susednih čvorova na izabranom putu, dobijeno imitacionim modeliranjem kretanja organizovanog kolonskog saobraćajnog toka $[2,3]$.

Vreme putovanja predstavlja srednje vreme kretanja simulirane kolone na određenoj dužini puta za ukupan broj simulacija. Ono uzima u obzir dubinu i druge specifičnosti kolone [4] i dobija se prema izrazu:

$\bar{t}_{k k}=\frac{L \cdot \bar{t}_{o k}}{\bar{D}_{k}}+\bar{t}_{o k}[\mathrm{~min}]$

gde je:

$\bar{t}_{k k}$ - srednje vreme kretanja kolone između čvorova $\mathrm{P}_{\mathrm{m}}$ i $\mathrm{P}_{\mathrm{n}}[\mathrm{min}]$,

$L$ - dužina puta između čvorova na mreži $[\mathrm{km}]$,

$\bar{t}_{o k}$ - srednje vreme opsluživanja kolone (kretanje na sopstvenoj dubini kolone, $\overline{\mathrm{D}}_{\mathrm{k}}$ ), dobijeno modeliranjem [min],

$\bar{D}_{k}$ - srednja dubina kolone $[\mathrm{km}]$.

Relacija (3) dobija sledeći oblik:

$T=\sum_{k=m}^{n} \frac{L \cdot \bar{t}_{o k}}{\bar{D}_{k}}+\bar{t}_{o k}[\mathrm{~min}]$

Zadatak određivanja minimalnog puta na mreži, između čvorova $\mathrm{P}_{\mathrm{m}}$ i $\mathrm{P}_{\mathrm{n}}$, jeste da se minimizira vreme putovanja između izabranih čvorova, predstavljeno relacijom (5).

Da bi vrema putovanja $\mathrm{T}$, odnosno $t_{k}$, bilo minimalno, vrednost merodavnog parametra mora biti optimalna. Pri određivanju optimalnog puta, u zavisnosti od relevantnog parametra, potrebno je izabrati deonice sa maksimalnim vrednostima: protoka $\mathrm{Q}$, brzine $\mathrm{V}$, koeficijenta prianjanja pneumatika $\mu$, i vrednostima uzdužnog nagiba puta $i$ što bliže 0 .

\section{Matematički model određivanja najkraćeg puta na mreži}

Problem određivanja najkraćeg puta na mreži između čvora $\mathrm{P}_{1}$ i čvora $\mathrm{P}_{\mathrm{N}}$, tj. dva unapred zadata čvora, klasičan je problem dinamičkog programiranja. Jedan od najpoznatijih algoritama za nalaženje najkraćeg puta od zadatog čvora $\mathrm{P}$ do ostalih čvorova u mreži jeste Belmanov algoritam $[5,6]$.

Algoritam se zasniva na uspostavljanju rekurentnih relacija između vrednosti kriterijumske funkcije $\mathrm{f}_{\mathrm{i}}^{\mathrm{k}}$ čvora $\mathrm{P}_{\mathrm{i}} \mathrm{i}$ čvora $P_{N}$. Veličina $f_{i}^{k}$ predstavlja dužinu najkraćeg puta između čvora $P_{i}$ i čvora $\mathrm{P}_{\mathrm{N}} \mathrm{u}$ koraku k. Rekurentna relacija je posledica principa optimalnosti i glasi:

$f_{i}^{k+1}=\min _{j \neq i}\left(x_{i j}+f_{j}^{k}\right), k=0,1,2, \ldots$

$f_{n}^{k+1}=0, \quad i=1,2, \ldots, n-1$.

Algoritam spada u grupu iterativnih, relaksacionih algoritama, u kojem se $\mathrm{u}$ svakoj iteraciji izračunava kriterijumska funkcija $f_{i}^{k} z a$ sve čvorove. Tokom itera- 
cija veličine $\mathrm{f}_{\mathrm{i}}^{\mathrm{k}}$ se menjaju, a proces je završen kada $u$ dve uzastopne iteracije kriterijumska funkcija $f_{i}^{k}$ svih čvorova bude ista.

Pri izračunavanju se polazi od puta koji direktno povezuje $\mathrm{P}_{\mathrm{i}}$ i $\mathrm{P}_{\mathrm{N}}$, a zatim se traži put od $\mathrm{P}_{\mathrm{i}}$ do $\mathrm{P}_{\mathrm{N}}$ sa dve grane, pa sa tri, itd.

Početno rešenje definisano je sledećim izrazima:

$$
\begin{aligned}
& f_{i}^{1}=X_{i n}, \quad i=1,2, \ldots, n-1 \\
& f_{n}^{1}=0 .
\end{aligned}
$$

U koraku $k=2$ vrši se izbor najkraćeg puta od čvora $\mathrm{P}_{\mathrm{i}}$ do čvora $\mathrm{P}_{\mathrm{N}}$, koji vodi preko jednog čvora. Tako se dobija novo rešenje:

$f_{i}^{2}=\min \left(x_{i j}+f_{i}^{1}\right) \quad i=1,2, \ldots, n-1$

$f_{n}^{2}=0$,

pri čemu je zadovoljena nejednakost:

$$
f_{i}^{2} \leq f_{i}^{1}, \quad i=1,2, \ldots, n-1
$$

Rešenje problema postiže se u k-toj iteraciji za koju važi relacija:

$$
\begin{aligned}
& f_{i}^{k}=f_{i}^{k+1}, i=1,2, \ldots, n-1 \\
& f_{n}^{k}=f_{n}^{k+1}=0 .
\end{aligned}
$$

Drugi deo algoritma, ucrtavanje optimalnog puta na mreži, odvija se prema sledećim koracima:

- uočavaju se svi čvorovi direktno povezani sa $\mathrm{P}_{\mathrm{i}}$ za koje u poslednjem koraku važi $\mathrm{f}_{1}<\mathrm{f}_{\mathrm{i}}$;
- optimalni put prolaziće kroz onaj sledeći čvor za koji važi relacija:

$f_{i}=x_{i j}+f_{j}$,

gde $\mathrm{j}$ dobija vrednosti $\mathrm{P}_{\mathrm{i}}$ onih čvorova koji su direktno povezani sa čvorom $\mathrm{P}_{1}$;

- prethodni postupak se ponavlja za čvorove za koje je zadovoljena relacija (11) i nastavlja do čvora $\mathrm{P}_{\mathrm{N}}$, tj. dok se ne ucrta čitav optimalni put. Ovaj postupak se ponavlja sve dok se ne ucrtaju sve varijante optimalnog puta, ukoliko je rešenje višestruko;

- ako se u relacijama (6) i (11) umesto dužine puta $\mathrm{x}_{\mathrm{ij}}$ između čvora $\mathrm{P}_{\mathrm{i}} \mathrm{i}$ čvora $P_{j}$ uvrsti vreme putovanja:

$t_{i j}=\frac{L \cdot \bar{t}_{o k}}{\bar{D}_{k}}+\bar{t}_{o k}$

dobija se:

$f_{i}^{k+1}=\min _{j \neq i}\left(\frac{L \cdot \bar{t}_{o k}}{\bar{D}_{k}}+\bar{t}_{o k}+f_{j}^{k}\right), k=0,1,2, \ldots$

$f_{n}^{k+1}=0, \quad i=1,2, \ldots, n-1$,

$f_{i}=\frac{L \cdot \bar{t}_{o k}}{\bar{D}_{k}}+\bar{t}_{o k}+f_{j}$

U prikazanom algoritmu postoji mogućnost izbora najkraćeg puta samo od čvora $\mathrm{P}_{\mathrm{N}}$ do ostalih čvorova u mreži. Međutim, mnogo češće se javlja potreba da se u postojećoj mreži odredi najkraći put za bilo koja dva čvora.

$\mathrm{Da}$ bi se to omogućilo postojećim modelom, potrebno je matricu rastojanja $\mathrm{X}$ transformisati tako da se red i kolona 
matrice zadatog početnog čvora $\mathrm{P}_{\mathrm{m}}$ prebace na mesto poslednjeg reda i kolone $\mathrm{P}_{\mathrm{N}}$.

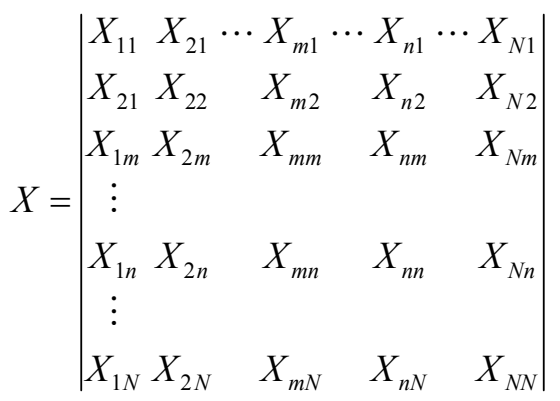

Nakon transformacije, nova matrica rastojanja $X_{1}$ ima oblik:

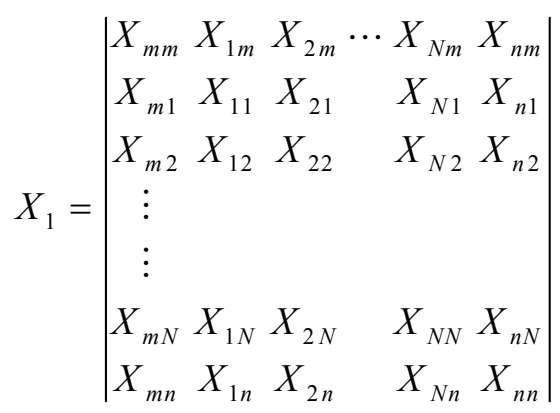

Nakon transformacije matrice rastojanja, Belmanov algoritam može se primeniti bez ikakvih promena.

\section{Algoritam za određivanje optimalnog puta}

Zadatak izbora optimalnog puta na osnovu rezultata imitacionog modeliranja, prema odabranom merodavnom parametru, rešen je u programskom jeziku „C“. Glavni program povezuje četiri potprograma:

- za izbor merodavnog parametra $\mathrm{i}$ određivanje optimalnog vremena putova- nja organizovane kolone, na osnovu rezultata imitacionog modeliranja;

- za preuređenje datoteke mesta i datoteke vremena putovanja;

- za određivanje minimalnog puta na mreži primenom dinamičkog programiranja, i

- za unos relevantnih podataka o putnoj mreži.

\section{Algoritam za izbor merodavnog} parametra i određivanje optimalnog vremena putovanja

Da bi model dinamičkog programiranja mogao nesmetano da radi, potrebno je za celu mrežu izračunati vremena putovanja u zavisnosti od uslova i stanja sistema $\mathrm{V}-\mathrm{V}-\mathrm{P}-\mathrm{O}-\mathrm{O}$, izraženih preko merodavnog parametra. Zbog toga, potprogram za izbor merodavnog parametra i izračunavanje vremena putovanja mora da prethodi potprogramu za izbor optimalnog puta.

Za rad ovog potprograma formirano je šest datoteka podataka:

- „KARTA“ - datoteka podataka o putevima na odabranoj mreži;

- „1DPSMO“ - datoteka numeričkih karakteristika sistema $\mathrm{V}-\mathrm{V}-\mathrm{P}-\mathrm{O}-\mathrm{O}$, zavisno od merodavnog protoka na mreži;

- „DPSMO1“ - datoteka numeričkih karakteristika sistema $\mathrm{V}-\mathrm{V}-\mathrm{P}-\mathrm{O}-\mathrm{O}$, zavisno od merodavne brzine na mreži;

- „DPSMO4“ - datoteka numeričkih karakteristika sistema $\mathrm{V}-\mathrm{V}-\mathrm{P}-\mathrm{O}-\mathrm{O}$, zavisno od merodavnih koeficijenata prianjanja pneumatika i kolovoza;

- „DPSMOI“ - datoteka numeričkih karakteristika sistema $\mathrm{V}-\mathrm{V}-\mathrm{P}-\mathrm{O}-\mathrm{O}$, za- 
visno od merodavnog uzdužnog nagiba puta na mreži;

- „TMIN“ - datoteka vremena putovanja za sve puteve na mreži, zavisno od odabranog merodavnog parametra.

Datoteke 1DPSMO, DPSMO1, DPSMO4 i DPSMOI formirane su u toku modeliranja kolonskog saobraćajnog toka. U ovom potprogramu se pomoću numeričkih karakteristika sistema $\mathrm{V}-\mathrm{V}-\mathrm{P}-$ $\mathrm{O}-\mathrm{O}^{*}$, određuje vreme putovanja za sve puteve na mreži prema izabranom merodavnom parametru.

Vreme putovanja za pojedine deonice puta na mreži pri kretanju saobraćajnog toka ne može se izračunati prostom analitičkom vezom između osnovnih veličina: puta, vremena i brzine, jer predstavlja idealizovan model saobraćaja koji važi samo za kretanje pojedinačnog vozila u idealnim uslovima [7]. Vreme putovanja je promenljiva veličina, koja zavisi od interakcija u sistemu $\mathrm{V}-\mathrm{V}-\mathrm{P}-\mathrm{O}-\mathrm{O}$ i velikog broja slučajno promenljivih faktora. Za kretanje kolonskih saobraćajnih tokova ono se realno može dobiti imitacionim modeliranjem prema izrazu (4). Zbog toga, iz podataka dobijenih modeliranjem, treba odrediti i uzeti u obzir parametre kolonskog saobraćajnog toka: srednje odstojanje između vozila u koloni, $\overline{\mathrm{l}}_{\mathrm{ps}}$; srednju dubinu kolone $\overline{\mathrm{D}}_{\mathrm{k}}$; srednju gustinu saobraćaja, $\overline{\mathrm{G}}$ i srednje vreme opsluživanja kolone $\overline{\mathrm{t}}_{\mathrm{ok}}$ [4].

U datoteci „KARTA“, za čvorove koji su direktno povezani, nalaze se sledeći podaci:

"Ove karakteristike dobijene su imitacionim modeliranjem kolonskog saobraćajnog toka [2, 3] i ovde se koriste kao baza podataka. Kretanje kolone posmatra se kao rad „sistema za masovno opsluživanje“ (SMO), pa ove datoteke sadrže podatke tipične za SMO.
- L (i,j) $[\mathrm{km}]$ - dužina puta između i-tog i j-tog čvora;

- Q (i,j) [voz/h] - maksimalni mogući protok između i-tog i j-tog čvora na mreži;

$-\mathrm{V}(\mathrm{i}, \mathrm{j})[\mathrm{km} / \mathrm{h}]$ - moguća brzina između i-tog i j-tog čvora na mreži, za kolonski tok;

- $\mu(\mathrm{i}, \mathrm{j})-$ koeficijent prianjanja pneumatika sa podlogom na deonici između i-tog i j-tog čvora na mreži;

- $\pm \mathrm{i}[\%]$ - uzdužni nagib puta, ,,+“ za uspon ,„-“ za pad, na deonici između i-tog i j-tog čvora na mreži.

$\mathrm{Za}$ čvorove koji nisu direktno povezani nalazi se podatak o dužini i to: $\infty$ za $i \neq j$ i 0 za $i=j$.

U datoteci ,TMIN“, na osnovu odabranog parametra, za sve direktno povezane čvorove, izračunava se i upisuje vreme putovanja $t_{i j}$, a za ostale čvorove upisuje se $\infty$ za i $\neq$ j i 0 za $i=j$.

$\mathrm{Na}$ slici 2 prikazan je opšti blokdijagram potprograma za izbor optimalne brzine kretanja i izračunavanja vremena putovanja.

\section{Algoritam za preuređenje datoteke}

mesta i datoteke vremena putovanja

Prema opisu problema, a radi uopštavanja modela tj. izbora puta za kretanje između bilo koja dva čvora na mreži, potrebno je izvršiti transformaciju matrice vremena putovanja $T=\left[\mathrm{t}_{\mathrm{ij}}\right]$.

Za rad ovog potprograma koristi se šest datoteka:

- „MESTA“ - nepromenljiva datoteka naziva čvorova - mesta na mreži;

- „MESTA2“ - promenljiva datoteka naziva čvorova na mreži; 


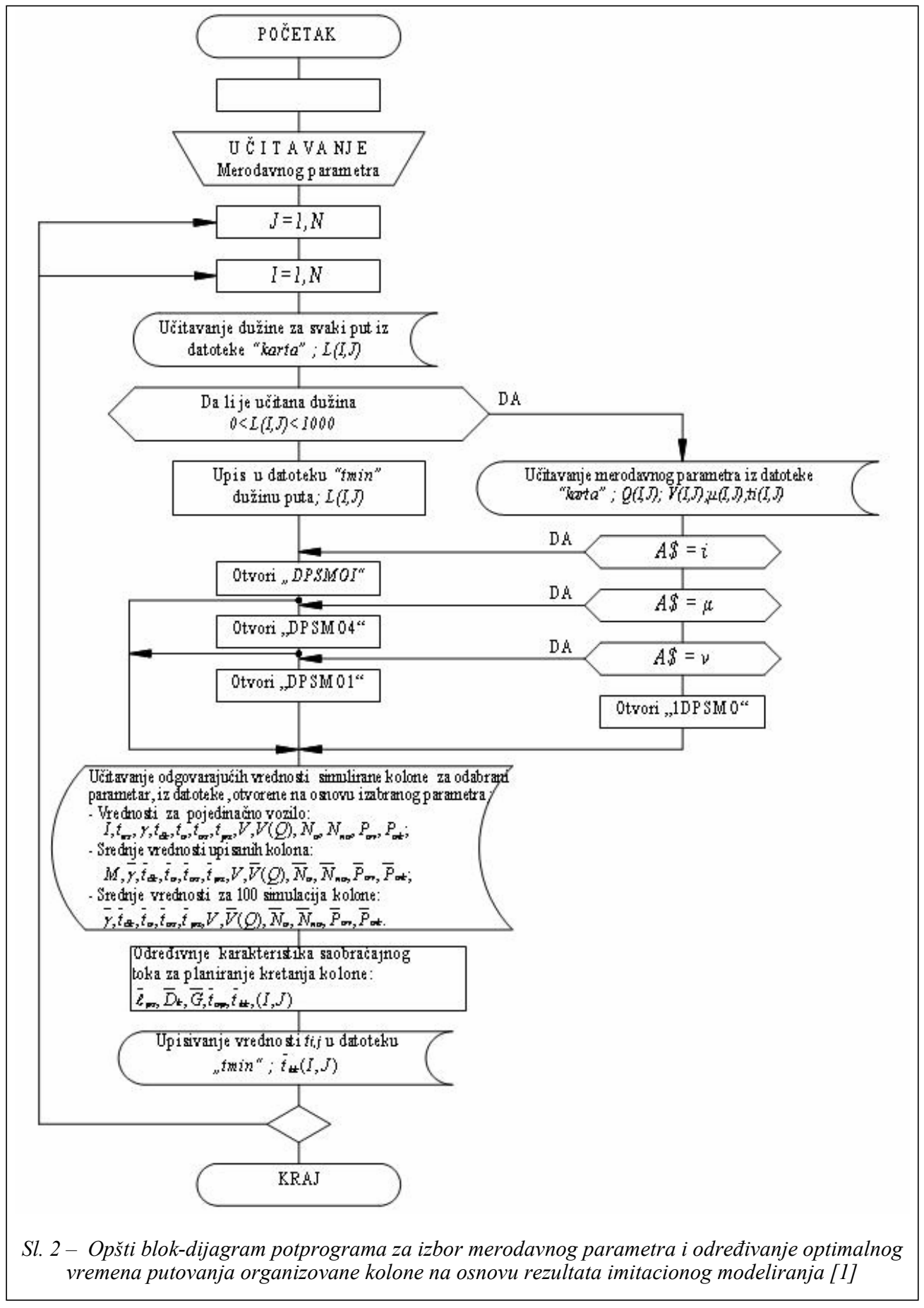


- „KARTA1“ - promenljiva pomoćna datoteka vremena putovanja;

- „KARTA2“ - promenljiva datoteka vremena putovanja;

- „TMIN“ - datoteka vremena putovanja, za sve puteve na mreži;

- „MESTA3“ - promenljiva datoteka za upis maršrute kretanja (početno i krajnje mesto).

Na osnovu opisanog postupka razrađen je algoritam za preuređenje datoteke mesta (naziva čvorova) i datoteke vremena putovanja.

Nakon upisa početnog i krajnjeg mesta i pronalaženja njihovih rednih brojeva m i n u datoteci „MESTA“, vrši se preuređenje datoteka „MESTA2“ i „KARTA2“. Najpre se preuređuje datoteka „MESTA2“ tako da na prvo mesto dolazi naziv čvora $\mathrm{m}$ (početno mesto), a na poslednje naziv čvora n (krajnje mesto). Datoteka „KARTA2“ preuređuje se tako što se m-ti red i kolona prebace na mesto prvog reda i kolone, dok se n-ti red i kolona prebace na mesto $\mathrm{N}$-tog reda i kolone ( $\mathrm{N}$ je broj mesta na putnoj mreži). Ako se zahteva izbor maršrute za iste čvorove, postupak preuređenja datoteka se preskače i zahteva unos validnih podataka (različito početno i krajnje mesto).

$\mathrm{Na}$ slici 3 prikazan je opšti blok-dijagram potprograma za preuređenje datoteke mesta i datoteke vremena putovanja.

\section{Algoritam za određivanje najkraćeg puta na mreži, između odabranih čvorova-mesta, primenom dinamičkog programiranja}

Nakon određivanja optimalne brzine, izračunavanja vremena putovanja i preuređenja datoteka, moguće je primeniti Belmanov algoritam dinamičkog programiranja za izbor najkraćeg puta.

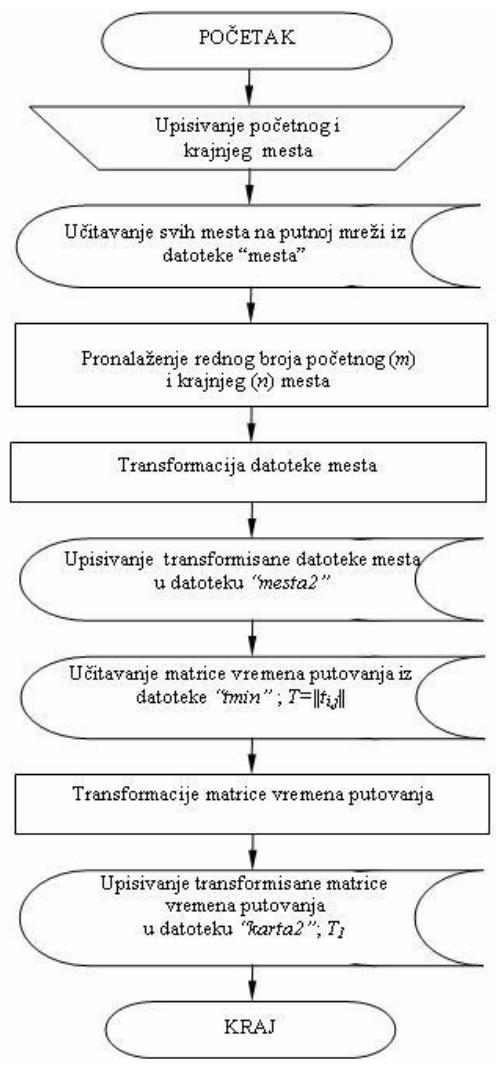

Sl. 3 -Opšti blok-dijagram potprograma za preuređenje datoteke mesta i datoteka vremena putovanja [1]

Za rad ovog potprograma koriste se četiri datoteke:

- „KARTA2“ - preuređena datoteka vremena putovanja;

- „MESTA2“ - preuređena datoteka naziva čvorova;

- „MESTA3“ - datoteka u koju je upisana maršruta kretanja (početno i krajnje mesto).

- „MESTA4“ - datoteka u koju se upisuju sva mesta, na određenoj, minimalnoj maršruti.

$\mathrm{Na}$ osnovu opisanog postupka razrađen je algoritam za izbor najkraćeg puta na mreži. 


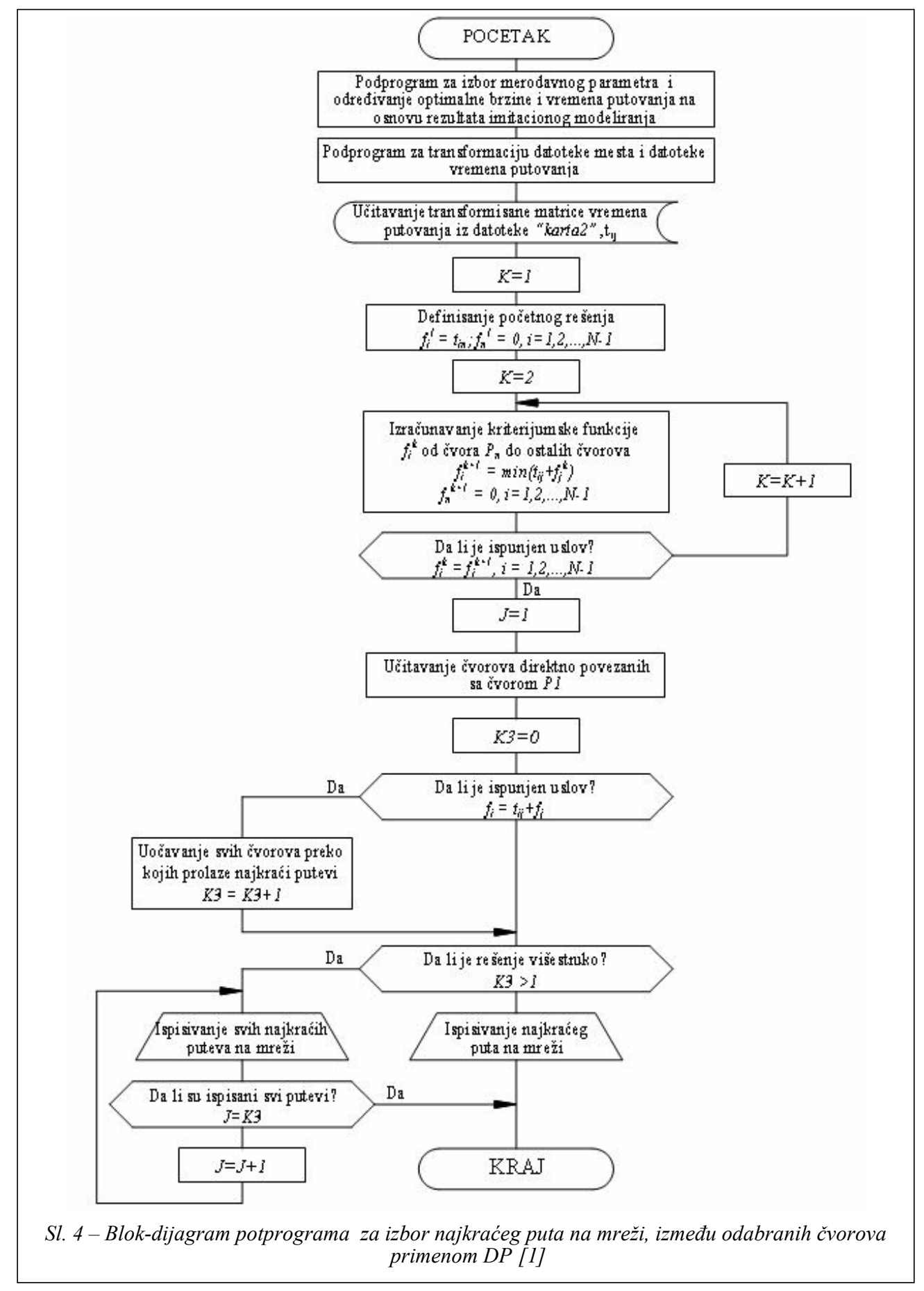




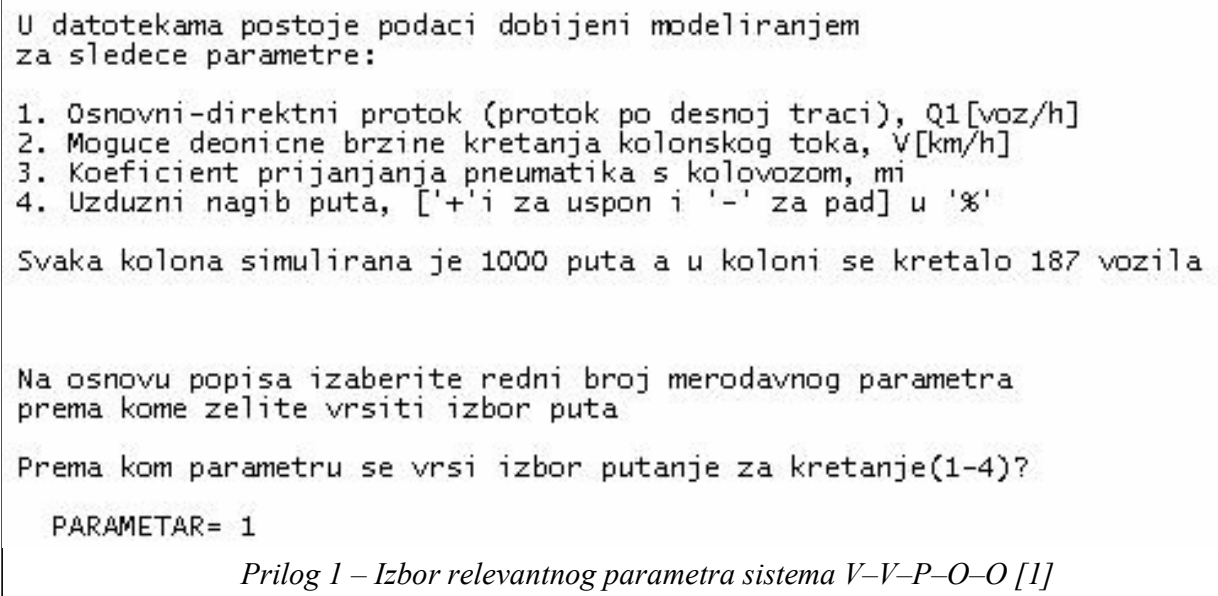

Algoritam ispisuje: vrednost kriterijumske funkcije $f_{i}^{k}$ za sve čvorove prema koracima izračunavanja, minimalno vreme putovanja izraženo u satima, relaciju kretanja $i$, na kraju, određuje $i$ ispisuje dužinu minimalne maršrute izraženu u kilometrima. Ukoliko je rešenje višestruko, ispisuju se podaci o svim određenim maršrutama.

Na slici 4 prikazan je opšti blok-dijagram potprograma za izbor najkraćeg puta na mreži, između odabranih čvorova - mesta, primenom dinamičkog programiranja.

Ovaj algoritam (slika 4) realizovan je kao konzolna aplikacija, u kojoj se od korisnika najpre zahteva da izabere relevantni parametar po kojem se vrši izbor optimalnog puta (prilog 1). Zatim, ispisuje nazive svih čvorova na putnoj mreži $i$ od korisnika zahteva da unese početno i krajnje mesto maršrute za kretanje kolone (prilog 2). Nakon toga, program ispisuje vrednosti parametarske funkcije $\mathrm{f}$, po koracima izračunavanja (prilog 3). Na kraju se ispisuju: minimalno vreme kretanja na izabranoj maršruti u satima, čvorovi putne mreže koji povezuju početno i
Cvorovi na putnoj mrezi:

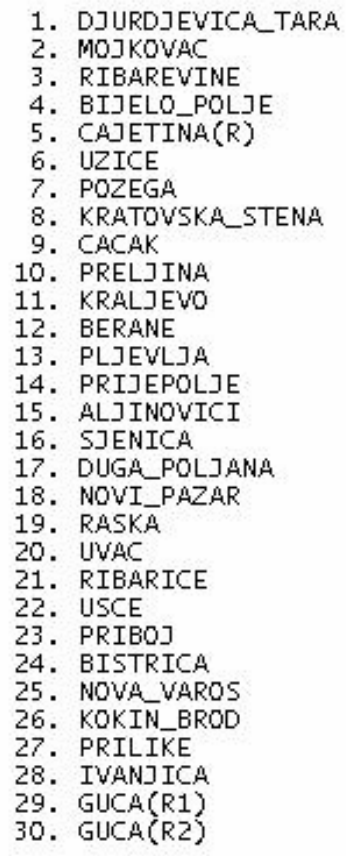

11. KRALJEVO

12. BERANE

13. PLJEVLJA

14. PRIJEPOLJE

15. ALJINOVICI

16. SJENICA

17. DUGA_POLJANA

18. NOVI_PAZAR

19. RASKA

20. UVAC

21. RIBARICE

22. USCE

23. PRIBOJ

24. BISTRICA

25. NOVA VAROS

26. KOKIN_BROD

27. PRILIKE

28. IVANJICA

29. GUCA(R1)

30. GUCA(R2)

Na osnovu popisa cvorova izaberite marsrutu kretanja za kolonu vozila.

Upisite pocetno mesto? MOJKOVAC Upisite krajnje mesto? IVANJICA

Prilog 2 -Definisanje početnog i krajnjeg čvora za izbor minimalne maršrute [1] 


\begin{tabular}{|c|c|c|c|c|c|c|c|c|c|c|c|c|c|}
\hline & \multicolumn{6}{|c|}{$\begin{array}{l}\text { Minimalna vremena putovanja izmedju IVANJICA } \\
\text { i ostalih cvorova u mrezi prema koracima izracunavanja }\end{array}$} \\
\hline 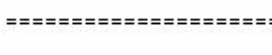 & & $k=\zeta$ & $k=3$ & $K=4$ & $K=$ & & & & & & & & \\
\hline \multicolumn{14}{|c|}{ 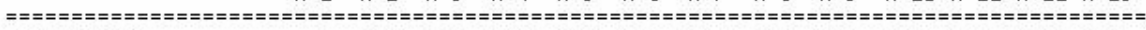 } \\
\hline 11 & 0 & 81 & 134 & 186 & 238 & 290 & 342 & & 446 & 498 & 50 & & \\
\hline A_T & 0 & 104 & 193 & 245 & & & & & & & & & \\
\hline & 0 & 57 & 10 & 156 & & & & & & & & & \\
\hline & 0 & $5 \overline{2}$ & 10 & & 20 & & & & & & כ & & \\
\hline & 0 & $7 \overline{2}$ & 14 & & 2 & & & & & & & & \\
\hline & 0 & $7 \overline{2}$ & & & 26 & & & & & & & & \\
\hline & $=$ & $5 \overline{7}$ & 11 & & 1 & & & & & & & & \\
\hline 8 & 0 & 57 & & & & & & & & & & & \\
\hline & 0 & 54 & & & & & & & & & & & \\
\hline & 0 & 54 & 10 & & & & & & & & & & \\
\hline & 0 & 100 & 15 & & & & & & & & & & \\
\hline & 0 & & 14 & & & & & & & & & & \\
\hline & 0 & 9 & 15 & & & & & & & & & & \\
\hline & 0 & 6. & 12 & 1 & & & & & & & & & \\
\hline & & 8 & 1 & & & & & & & & & & \\
\hline & $15 \overline{2}$ & $\therefore$ & 15 & 15 & 15 & & & 15 & 1 & & 15 & & 1 \\
\hline & & 9 & & & & & & & & & & & \\
\hline 年 & & 79 & 15 & 2 & 24 & 2 & & 2 & & & 243 & & 243 \\
\hline & & 70 & & & & & & & & & & & \\
\hline & 0 & 51 & 10 & 15 & 20 & & & & & & & 4 & 440 \\
\hline$E$ & & 87 & & & & & & & & & & & \\
\hline & 138 & 88 & 1 & 13 & 13 & & & 1 & & & & & \\
\hline & & & & & & & & & & & & & \\
\hline & 0 & 61 & 12 & 17 & 22 & & & & & & & & \\
\hline & & & & & & & & & & & & & \\
\hline QuD & 0 & 59 & 117 & 176 & 189 & 18 & 189 & 18 & 189 & 189 & 189 & 189 & 189 \\
\hline & & & & & & & & & & & & & \\
\hline 28. & 91 & 61 & 91 & 91 & 9 & 9 & 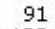 & 9 & & 91 & 91 & 1 & 91 \\
\hline & & 78 & 12 & & 15 & & & & & & & & 153 \\
\hline$A \otimes \perp C A$ & & & & & & & & & & & & & \\
\hline
\end{tabular}

$====$ = = = = = = = = = = = = = =

Minimal no vreme putovanja $9.45 \mathrm{~h}$

Minimalna marsruta izmedju MOJKOVAC i IVANJICA

1.MOJKOVAC

2. BERANE

3. RIBARICE

5. DUGA_POLJANA

6. IVANJICA

Duzina marsrute je $228 \mathrm{~km}$

Prilog 3 - Prikaz minimalnih rezultata za izabranu maršrutu [1]

krajnje mesto izabrane maršrute i dužina maršrute u kilometrima (prilog 3). U prilozima 1, 2 i 3 prikazan je ispis programa za izabrani merodavni parametar sistema $\mathrm{V}-\mathrm{V}-\mathrm{P}-\mathrm{O}-\mathrm{O}$, „osnovni-direktni protok (protok po desnoj kolovoznoj traci)“ $\mathrm{i}$ Mojkovac kao početno, a Ivanjica kao krajnje mesto [1]. Kao što se vidi iz priloga 3, za izabrani parametar se dobija: minimalno vreme kretanja 9,45 h, minimalna maršruta: „Mojkovac - Berane Ribariće - Novi Pazar - Duga Poljana Ivanjica, dužine $228 \mathrm{~km}$. Ako korisnik, kao relevantni parametar sistema $\mathrm{V}-\mathrm{V}-$ $\mathrm{P}-\mathrm{O}-\mathrm{O}$, izabere moguću brzinu kretanja na pojedinim deonicama, kao izlaz se dobija: minimalno vreme kretanja 16,34 h, minimalna maršruta: „Mojkovac - Ribarevine - Bijelo Polje - Prijepolje - Bistrica - Nova Varoš - Kokin Brod - Čajetina - Užice - Požega - Prilike - Ivanjica“ dužine $248 \mathrm{~km}$. U slučaju izbora koeficijenta prianjanja pneumatika kao relevantnog parametra sistema $\mathrm{V}-\mathrm{V}-\mathrm{P}-$ $\mathrm{O}-\mathrm{O}$ na izlazu se dobijaju sledeće vrednosti: minimalno vreme kretanja 9,13 h, 
minimalna maršruta: „Mojkovac - Ribarevine - Bijelo Polje - Prijepolje - Aljinovići - Sjenica - Ivanjica“ dužine 193 km. Na kraju, za izbor uzdužnog nagiba puta kao relevantnog parametra sistema $\mathrm{V}-\mathrm{V}-\mathrm{P}-\mathrm{O}-\mathrm{O}$, vreme kretanja kolone je $9,13 \mathrm{~h}$, a ostale vrednosti parametara puta identične su kao u slučaju izbora koeficijenta prianjanja pneumatika sa podlogom, kao relevantnog parametra sistema V-V-P-O-O. Na osnovu prikazanih i navedenih podataka može se zaključiti da se za različite izabrane parametre, a isto početno i krajnje mesto, dobijaju različiti rezultati.

\section{Zaključak}

Cilj ovog projekta jeste da se SbP, ali i proces rukovođenja i komandovanja, učine što efikasnijim. Korisnik bi, upotrebom ovog sistema, mnogo brže i lakše donosio odluke. To bi sistem funkcionisanja logističke podrške i sistem komandovanja u celosti učinilo efikasnijim.

U kasnijem razvoju moguće je poboljšanje funkcionalnosti ovog sistema. Program se može poboljšati tako da korisnik - operater zadaje određene uslove i ograničenja koja bi se uzimala u obzir pri izračunavanju optimalnog puta. Model izbora optimalnog puta treba usavršiti prema realnim zadacima SbP. Vojska ima potrebe da se kreće u raznim uslovima i uz različita ograničenja, pa zadaci optimizacije mogu biti uslovljeni. Na primer, potrebno je odrediti minimalnu maršrutu između dva mesta na putnoj mreži, uz uslov da kolona prođe kroz određeno mesto (usputni utovar, istovar, ukrcavanje, iskrcavanje i sl.), ili da zbog određenih ograničenja izbegne kretanje kroz određeno mesto (srušen most, tučena deonica, snežni nanosi, nedovoljan kapacitet i sl.). Pored toga, sistem se može unaprediti i izradom odgovarajućeg grafičkog korisničkog interfejsa.

Literatura:

[1] Gordić, S. R.: Efikasnost organizovanog vojnog kolonskog saobraćajnog toka, doktorska disertacija, Vojna akademija, Škola nacionalne odbrane, Beograd, 2005.

[2] Gordić, S. R.: Izračunavanje osnovnih karakteristika rada puta kao sistema masovnog opsluživanja, seminarski rad iz predmeta Operaciona istraživanja I, TVA PDS, Zagreb, 1981.

[3] Gordić, S. R.: Modeliranje kretanja organizovanog kolonskog saobraćajnog toka, Simpozijum sa međunarodnim učešćem Optimizacija razvoja saobraćajnog sistema Jugoslavije, zbornik radova, Beograd, 1990.

[4] Gordić, S. Radomir: Operativno planiranje saobraćaja na putevima kod kolonskih kretanja, Vojnotehnički glasnik, br. 2, 1983.

[5] Petrović, R.: Specijalne metode u optimizaciji sistema, Tehnička knjiga, Beograd, 1977.

[6] Калихман, И. Ј. и сот.; Динамическое програмирование в примерах и задачах, Москва, Высшая школа, 1979.

[7] Kuzović, Lj.; Teorija saobraćajnog toka, IRO Građevinska knjiga, Beograd, 1987. 